\title{
CLEAN DEVELOPMENT MECHANISM: PERSPECTIVES FROM DEVELOPING COUNTRIES
}

\author{
Agus P. Sari \\ Energy and Resources Group, \\ University of California at Berkeley, 310 Barrows Hall, \\ Berkeley, CA, USA and \\ Pelangi Indonesia, Jakarta, Indonesia. \\ Email: apsari@socrates.berkeley.edu. \\ Stephen Meyers \\ Energy Analysis Department, \\ Environmental Energy Technologies Division \\ Lawrence Berkeley National Laboratory, \\ Berkeley, USA. \\ Email: spmeyers@lbl.gov
}

May 1999

This work was supported by the U.S. Environmental Protection Agency through the U.S. Department of Energy under Contract No. DE-AC03-76SF00098. 


\title{
Clean Development Mechanism: Perspectives from Developing Countries
}

\author{
Agus P. Sari and Stephen Meyers
}

\begin{abstract}
This paper addresses the political acceptability and workability of CDM by and in developing countries. At COP-3 in Kyoto in 1997, the general position among developing countries changed from strong rejection of joint implementation to acceptance of CDM. The outgrowth of CDM from a proposal from Brazil to establish a Clean Development Fund gave developing countries a sense of ownership of the idea. More importantly, establishing support for sustainable development as a main goal for CDM overcame the resistance of many developing countries to accept a carbon trading mechanism. The official acceptance of CDM is not a guarantee of continued acceptance, however. Many developing countries expect CDM to facilitate a substantial transfer of technology and other resources to support economic growth. There is concern that Annex I countries may shift official development assistance into CDM in order to gain carbon credits, and that development priorities could suffer as a result. Some fear that private investments could be skewed toward projects that yield carbon credits.

Developing country governments are wary regarding the strong role of the private sector envisioned for CDM. Increasing the awareness and capacity of the private sector in developing countries to initiate and implement CDM projects needs to be a high priority. While private sector partnerships will be the main vehicle for resource transfer in CDM, developing country governments want to play a strong role in overseeing and guiding the process so that it best serves their development goals. Most countries feel that establishment of criteria for sustainable development should be left to individual countries. A key issue is how CDM can best support the strengthening of local capacity to sustain and replicate projects that serve both climate change mitigation and sustainable development objectives.
\end{abstract}

There is support among developing countries for commencing CDM as soon as possible. Since official commencement must await the entry into force of the Kyoto Protocol, many developing countries support the establishment of an Interim Phase starting in 2000, with possible retroactive crediting once the Protocol enters into force.

\section{INTRODUCTION}

The 1997 Kyoto Protocol to the 1992 United Nations Framework Convention on Climate Change (UN-FCCC) provides a first step towards reducing the future risks of climate change. An important component of the Protocol is the stipulation for a collective emissions reduction objective by the countries listed in Annex I of the FCCC ${ }^{1}$ of 5.2 percent below their levels in

\footnotetext{
${ }^{1}$ Industrialized countries listed in Annex I are: Australia, Austria, Belarus*, Belgium, Bulgaria*, Canada, Czechoslovakia*, Denmark, European Economic Community (Now European Union), Estonia*, Finland, France, Germany, Greece, Hungary*, Iceland, Ireland, Italy, Japan, Latvia*, Lithuania*, Luxembourg, Netherlands, New
} 
1990, taking as a basis their emissions average in the period between 2008 and 2012 of greenhouse gases. The Quantified Emissions Limitation and Reduction Objectives (QELROs), as the Protocol called them, range from 8 percent for the European Union member countries collectively, 7 percent for the United States, 6 percent for Japan, stabilization for the Russian Federation and most countries with transitional economies, to an increase of 8 percent for Australia and 10 percent for Iceland. ${ }^{2}$

In meeting these objectives, there are four flexibility mechanisms under the Kyoto Protocol that can be utilized by these industrialized countries: "Bubble" Mechanism (Article 4), Emissions Trading (Article 17), Joint Implementation (Article 6), and Clean Development Mechanism (Article 12). Bubble Mechanism refers to the European Union member countries that agreed to have a collective QELRO of 8 percent, regardless of the actual individual countries' reductions. Emissions Trading (ET) refers to exchanging assigned amount of emissions between Annex I countries, expectedly between rich Annex I countries. Joint Implementation (JI) involves investment by an Annex I country in another Annex I country, with emissions reductions that are credited to the investing country. Clean Development Mechanism (CDM), the focus of this paper, is a mechanism similar to JI, except that it applies only for investment in developing countries, or countries not included in Annex I of FCCC. CDM also contains provisions for channeling funds to support adaptation to climate change.

Being a newly coined mechanism, CDM has a vast opportunity to be further shaped so that the benefits are enhanced and the costs are minimized. Michael Grubb, of the Royal Institute for International Affairs in the United Kingdom, states of CDM that if "handled well, [it] could provide substantial new financial resources to assist developing countries to develop along cleaner paths. It may also help them adapt to the effects of climate change, and bring local as well as global environmental and social benefits in accordance with their development needs. Handled badly, it could dump an everlasting supply of 'hot tropical air' into the trading mechanism proposed for implementing Annex I commitments, just as negotiators are struggling to remove the threat of Russian 'hot air.",3

Deemed as the "Kyoto surprise," CDM is the only link between the Kyoto Protocol and developing countries. Its workability will help ensure the effectiveness of the Kyoto Protocol and of developing countries' willingness to participate in a future global emissions regime. ${ }^{4}$ Since emissions from developing countries will eventually surpass those from the Annex I countries, developing countries full participation in such a regime is crucial.

Among developing countries, there is a spectrum of opinion regarding CDM, as there are different interests among the developing countries. While all developing countries hold a common position that its function is first and foremost to foster sustainable development, the African countries are particularly concerned about how this function remains very ill defined. ${ }^{5}$

Zealand, Norway, Poland*, Portugal, Romania*, Russian Federation*, Spain, Sweden, Switzerland, Turkey, Ukraine, United Kingdom of Great Britain and Northern Ireland, United States of America. Note: * Countries that are undergoing the process of transition to a market economy. See UNGA [United Nations General Assembly] (1992). United Nations Framework Convention on Climate Change. Rio de Janeiro, Brazil: United Nations Conference on Environment and Development. Hereinafter referred to as Climate Change Convention.

${ }^{2}$ Kyoto Protocol, Annex B.

${ }^{3}$ Grubb, M. (1997) “The Clean Development Mechanism.” ECO (December 9): 3.

${ }^{4}$ For example, Humphreys, S., Y. Sokona, and J-P. Thomas (1998). Equity in the CDM. Dakar, Senegal: ENDA TM.

${ }^{5}$ See, for example, ENDA TM Energy Program (1998). From Joint Implementation to the Clean Development Mechanism: Should African Positions Change After the Kyoto Protocol? Dakkar, Senegal: ENDA TM; also, Humphreys, S., et al., see footnote 4. 
The small island as well as the low-lying deltaic countries, due to their vulnerability, would like to protect its function as a mechanism to provide funds for adaptation to climate change. Some Latin American countries would like to promote the use of forestry projects - forest protection, reforestation, afforestation, and plantation - within CDM.

Among the industrialized countries, the positions are also diversified. Most of them, however, highlight its function as a producer of Certified Emissions Reductions (CERs). European countries suggest limiting the portion of the QELRO that can be bought from abroad, either through the purchase of Emissions Reduction Units (ERUs) from ET and JI, or CER from CDM, whereas the United States, Japan, and some other industrialized countries argue against any limitation. The EU argues that the limitation is necessary to ensure that Annex I countries still achieve significant reduction in their emissions domestically. ${ }^{6}$ The US position in promoting unlimited use of flexible mechanisms is based on the argument that these mechanisms will speed up the emissions reduction efforts while pushing the costs down: unnecessarily arbitrary limitation will hinder such benefits. ${ }^{7}$ All industrialized countries agree, however, that clear rules, procedures, and strong compliance mechanism are instrumental in the development of the CDM.

Ensuring the continuing acceptance and workability of CDM among developing countries is imperative. This paper addresses the issues of political acceptability and workability of CDM by and in developing countries. The underlying questions addressed in this paper are the following: Is CDM workable? How? What are the factors that will determine the acceptability by developing countries of CDM operation and governance?

This paper presents an overview of developing country perspectives on CDM, observed from published materials by developing country institutions, other published materials on developing country perspectives, personal communication with key informants, and close observation of the negotiation process on CDM. The perspectives described are generalizations made by the authors based on the above sources, and are not intended to represent the perspective of all developing country governments, or the official position of developing country groups such as the G77. ${ }^{8}$

\section{CDM AND ITS ORIGINS}

$\mathrm{CDM}$ is a product of a rushed eleventh hour of negotiation at the COP3 in Kyoto in December 1997. As Farhana Yamin of the Foundation for International Environmental Law and Development notes, "no Party's proposals resemble the CDM." Prior to Kyoto, there were no published papers about it. "The CDM is very much a creation of political necessity drawing on Brazilian proposals concerning the Clean Development Fund and various proposals concerning joint implementation. Its details were worked out in informal contact groups in the last few days of Kyoto, spearheaded by the Brazilian delegation with US support. Its final inclusion in the Protocol is intimately linked to trade-offs and deals struck between countries over apparently

\footnotetext{
${ }^{6}$ UNFCCC (1998). Matters Related to Decision 1/CP.3 Paragraph 5, Article 6 of the Kyoto Protocol, Article 12 of the Kyoto Protocol, Article 17 of the Kyoto Protocol, Activities Implemented Jointly: Compilation of Submissions by Parties. Document No. FCCC/CP/1998/MISC.7.

${ }^{7}$ Remarks by Mr. Stuart E. Eizenstat, head of the United States negotiating delegation at COP-4 in Buenos Aires, Argentina (November 12, 1998).

8 The first author was a non-governmental observer at Kyoto and a member of the Indonesian negotiating team at the subsequent Subsidiary Bodies Meeting in Bonn and the Fourth Conference of the Parties to the Climate Convention (COP4) in Buenos Aires.
} 
unrelated issues. And much of the detail of how it will work has been left to future negotiations at COP4 and beyond."'9

The Clean Development Fund (CDF) was a compliance mechanism proposed by Brazil in a meeting of the Ad Hoc Group on Berlin Mandate in 1997 (just prior to COP3 in Kyoto). Under the CDF proposal, Parties who fail to comply with their assigned emissions commitments in a given budget period are penalized through a requirement to contribute to the $\mathrm{CDF}$. In turn, the proceeds accumulated in the $\mathrm{CDF}$ are used by developing countries to foster sustainable development. A fraction of the proceeds, no more than 10 percent, would go to support adaptation measures in vulnerable countries.

At COP3 in Kyoto, CDM evolved into a mechanism for Annex I countries to gain emissions offsets to achieve their QELROs. Developing countries, however, highlight CDM's function to assist them to achieve sustainable development, and see it as a new channel for financial assistance, investments, technology transfer, and promotion of equity. Article 12 of the Kyoto Protocol defines the dual purpose of the CDM as follows:

- to assist Parties not included in Annex I in achieving sustainable development and in contributing to the ultimate objective of the Convention, and

- to assist Parties included in Annex I in achieving compliance with their quantified emission limitation and reduction commitments under Article 3.

CDM projects should be based on voluntary participation by each Party. Emissions reduction is accounted for on a project-by-project basis. Points (b) and (c) of Article 12.5 stipulate the criteria for determining Certified Emissions Reductions (CERs) for a CDM project. They should demonstrate "real, measurable, and long-term benefits," while the reductions should be "additional to any that would occur in the absence" of the project. The hypothetical situation that would occur in the absence of the project forms the baseline, whereas the reduction in emissions due to the project from an agreed and credible baseline is considered "additionality." Once the emissions reduction is certified by the Executive Board of CDM or by authorized third party, it can be transferred to the investing country as CERs. The investing countries may use the CERs to contribute to compliance with their QELROs.

CDM is to be guided by the Conference of the Parties to FCCC, serving as the meeting of the parties to the Kyoto Protocol (COP/MOP), and supervised by an Executive Board. COP/MOP shall elaborate modalities and procedures with the objective of ensuring transparency, efficiency, and accountability through independent auditing and verification of project activities. Subject to guidance provided by an Executive Board, either private or public entities may participate in CDM.

What is unique about CDM that is absent in other flexible mechanisms is that the CERs obtained during the period from 2000 up to 2008 can be used to assist in achieving compliance in the first commitment period. In addition, a fraction of the proceeds from sale of CERs is to be used to assist developing country Parties that are particularly vulnerable to the adverse effects of climate change to meet the costs of adaptation. This provision was carried out of the CDF proposal.

\footnotetext{
${ }^{9}$ Yamin, F. (1998) Issues and Options for Implementation of the Clean Development Mechanism. London, UK:

Foundation for Environmental Law and Development: 3
} 


\section{The Evolution of Political Acceptance of CDM}

$\mathrm{CDM}$ is similar to JI as a project-based mechanism that Annex I countries can use to offset domestic emissions. However, while JI was rejected by the G77 and China, CDM has been embraced. Observing the evolution from JI to CDM and the factors that contributed to rejection of JI and acceptance of CDM is instructive.

\section{Comparison between JI and CDM}

It is instructive to find similarities and differences that finally shifted most developing countries' positions from rejecting JI to embracing CDM. ${ }^{10}$ The following table summarizes the similarities and differences between JI and CDM.

\section{Table 1.}

Comparison between Joint Implementation and Clean Development Mechanism

\begin{tabular}{|c|c|c|}
\hline & Joint Implementation & $\begin{array}{l}\text { Clean Development } \\
\text { Mechanism }\end{array}$ \\
\hline Proposing agents & $\begin{array}{l}\text { Annex I countries (Germany and } \\
\text { Norway). }\end{array}$ & $\begin{array}{l}\text { Developing countries } \\
\text { (originated from proposal by } \\
\text { Brazil, elaborated by the G77 } \\
\text { and China, and tabled as G77 } \\
\text { and China's proposal). }\end{array}$ \\
\hline $\begin{array}{l}\text { Emphasis on sustainable } \\
\text { development }\end{array}$ & Implicit & Explicit \\
\hline $\begin{array}{l}\text { Coverage of adaptation } \\
\text { measures }\end{array}$ & Absent & Exists \\
\hline Banking of credits & Absent & Exists \\
\hline Emissions trading scheme & Entirely & Prominent \\
\hline $\begin{array}{l}\text { Transfer of resources and } \\
\text { technology }\end{array}$ & Expected & Expected \\
\hline Crediting scheme & Project-based & Project-based \\
\hline
\end{tabular}

The striking similarities between JI and CDM are that the two are expected to facilitate transfer of resources and technology from Annex I to developing countries and that the crediting scheme is project-based. Both are emissions trading mechanisms.

A key difference is that CDM explicitly states its function to foster sustainable development. Developing country delegates iteratively emphasize this feature as the most prominent one in CDM. Indeed, developing countries argue that CDM is first and foremost a mechanism to foster sustainable development. The second difference is the inclusion of adaptation measures as something CDM should support. The inclusion of this provision increases the acceptance of CDM by small-island and other similarly vulnerable developing countries.

\footnotetext{
${ }^{10}$ Not all developing countries rejected JI. On the forefront of those who did not reject and probably even welcomed JI were a good number of Latin American countries, especially Costa Rica. The ones who most strongly rejected JI were China and India.
} 
Finally, one of the most important differences is the origin of the schemes. JI originated from proposals by Germany and Norway; CDM, however, was an eventual result of a long evolution from a proposal by Brazil, a leading developing country. For most developing countries, this is an important difference.

\section{Contribution of AIJ}

When the negotiation for JI to be applied to developing countries came to a dead-end, AIJ was proposed as a JI pilot phase without crediting. Experience gained from the implementation of AIJ has reduced developing countries' skepticism regarding foreign-invested emissions reduction projects.

In 1995, AIJ was introduced amid strong rejection of JI by developing countries at COP1 in Berlin. AIJ was termed as a JI pilot phase, to run until the year 2000 when it is due for evaluation. It was included as part of the Berlin Mandate. AIJ projects are designed to allow investors and host countries to gain experience with project implementation and development of project criteria, and implementation of rules and guidelines. By the year 2000, some projects may provide retroactive credits, but there is no guarantee. In sum, AIJ is a version of JI without any exchange of emissions credit. Since there is no emissions credit, developing countries were willing to accept AIJ.

As with CDM a non-trivial factor for AIJ was the origin of the term. AIJ was coined by the Malaysian delegation to distinguish it from JI. Moreover, it was adopted as part of the Berlin Mandate, which is considered as a developing country proposal. The Berlin Mandate was the result of a lengthy negotiation from a proposal that was coined as the "China and India Paper." The apparent leadership of the developing countries in shaping AIJ seems to be a key factor behind its acceptance. This factor, analyzed later in this paper, seems also to be the case with CDM.

A key factor behind acceptance of AIJ is that it was a pilot scheme without any immediate expectation of crediting. While the absence of crediting has reduced private sector interests in investing in AIJ, it has also reduced the hesitation among the developing countries to participate in it. The main problem with JI from the developing countries' perspective was the provision of crediting. Some developing countries perceive this provision as transferring responsibility to limit emissions from Annex I to developing countries.

The third, and apparently quite significant, way in which AIJ contributed to acceptance of CDM is the actual flow of resources in AIJ projects. At the end of 1998, about 95 AIJ projects were reported, up from only 37 in 1997. About two-thirds are undertaken developed country Parties as investors and countries with economies in transition as hosts. Among developing countries, Costa Rica leads with 8 projects, whereas there is only one project in all Africa, in Burkina Faso. Overall, most of the projects are in the energy sector: 40 projects in renewable energy and 36 projects in energy efficiency. With 11 projects, forestry projects claim to account for 52 percent of the total emissions that will be reduced or sequestered. ${ }^{11}$

Finally, in undertaking AIJ projects, the local benefits of the projects have started to materialize and have helped persuade developing countries of the benefits of such projects. Lessons were learned from good and bad projects alike. Based on the experiences, various issues eventually were taken into account when the CDM proposal was crafted and negotiated.

\footnotetext{
${ }^{11}$ UNFCCC (1998). Review of the Implementation of Commitments and of Other Provisions of the Convention, Activities Implemented Jointly: Review of Progress Under the Pilot Phase (Decision 5/CP.1), Second Synthesis Report on Activities Implemented Jointly, Note by the Secretariat. Document No. FCCC/CP/1998/2.
} 


\section{ISSUES AND CONCERNS OVER CDM: OVERVIEW}

Ensuring a continued acceptance of CDM by developing countries requires taking fully into account these countries' concerns in the climate negotiations - or any international negotiation for that matter. There are at least five major philosophical concerns that underlie all of developing countries negotiating positions, and are the bases for their acceptance of any international agreement. The concerns are protected sovereignty, trust, sustained and noncompromised development, transfer of resources and technology, and promotion of equity. ${ }^{12}$

Sovereignty. Most of the developing countries are young countries, many of which obtained their independence from their Western colonizers in the 1950s. The legacy of colonialism renders them to be particularly sensitive to foreign influences. For them, sovereignty means not only in territorial terms, but also in terms of development, politics, and policy planning. Thus, the developing country governments seek some degree of supervision of the CDM process. The notion of "national sovereignty" has been applied to environmental concerns since the 1972 World Conference on Environment and Development in Stockholm, and reaffirmed in the FCCC and Principle 2 of the Rio Declaration. ${ }^{13}$

Trust. Developing countries are reluctant to embark on a deal if they feel that the real motives are strikingly different from the stated ones, if the alleged real motives might hurt them, and if they feel that they might be betrayed in the future. The loss of trust that has occurred in the climate negotiations means that support for CDM cannot be taken for granted if it seems that others are benefiting more. In the climate change negotiations, distrust was enhanced by the US insistence for "meaningful participation from "key" developing countries. This call for developing country participation disregards the Climate Convention and the Berlin Mandate agreements that the US actively participated in shaping. An overwhelming majority of developing countries reject any limitation of their future emissions. Exemption of developing countries from provisions to limit emissions is already included in the Convention, and was reaffirmed by the Berlin Mandate. This call broke developing countries' trust in the negotiating process. Even though CDM is officially accepted, this distrust is still effectively there, and could undermine the acceptance of CDM.

Sustained Development. Most developing countries are struggling to get out of poverty, which they view as caused partly by colonial exploitation. Alleviation of poverty and ensuring the availability of basic needs to their population are currently the main focus of their development process. This process is in no way to be compromised by foreign environmental interests. If CDM does not make its expected contribution to sustainable development, support for it is likely to erode.

\footnotetext{
${ }^{12}$ Gupta, J., R.v.d. Worff, G. Junne, M. Hisschemoller, and P. Vellinga, (1994). International Policies to Address The Greenhouse Effect. Working Paper No. 3. Amsterdam, the Netherlands: University of Amsterdam and Institute for Environmental Studies, vrije Universiteit Amsterdam.

${ }^{13}$ In Agenda 21, “... States have, in accordance with the charter of the United Nations and the principles of international law, the sovereign right to exploit their own resources pursuant to their own environmental and developmental policies, and the responsibility to ensure that activities within their jurisdiction or control do not cause damage to the environment of other States or of areas beyond the limits of national jurisdiction." See UNCED [United Nations Conference on Environment and Development] (1992). Earth Summit: Agenda 21, The United Nations Programme of Action From Rio. Rio de Janeiro, Brazil: United Nations Conference on Environment and Development: 9 .
} 
Transfer of Resources. In pursuing development, developing countries need as much resources and technology as possible. Many developing countries expect substantial transfer of resources through CDM as a realization of support for sustainable development.

Equity. In dealing with more advanced, industrialized, and rich countries, developing countries are cautious. They tend to ask questions such as: who will benefit more from this deal? Developing countries argue that if QELROs of Annex I countries were assigned equitably (such as on a per capita basis), then the overall QELROs would be much deeper than the ones currently stipulated in the Protocol. More stringent QELROs would lead to more demand for flexibility mechanisms, including the use of CDM, to meet them. In turn, more demand upon CDM would induce more flow of resources from Annex I to developing countries.

For CDM to be fully accepted, there also needs to be an equitable geographical distribution of projects. As mentioned above, out of 95 AIJ projects registered by FCCC up to 1998 , only one AIJ project was developed in Africa. CDM is understood to some extent as a vehicle for private investment: there is concern that projects will go where investors see the best opportunity for investment. Usually, these are countries where there is already a significant amount of Foreign Direct Investment (FDI). Africa, for example, only receives 3 percent of the world's FDI, and is thus expected to receive the least interest from investors. ${ }^{14}$

While CDM is accepted in principle, much still needs to be done to ensure its workability as a mechanism to serve its dual goals of emissions reduction and sustainable development. The following points summarize the issues that need attention. Further discussion on these issues is in the rest of the paper.

Credibility of CERs. The viability and credibility of CERs is determined by the credibility of the baseline, the calculation of additionality, and the soundness of the project itself. A noncredible process of certifying the emissions reduction will threaten the CDM.

Determining a Baseline. The emissions reduction credited to CDM projects should be measured from hypothetical emissions that would have otherwise occurred without such projects. Given the dynamic of the developing economies, establishing a credible baseline is a great challenge.

Additionality. It is necessary to establish a fair and reasonable objective method to judge whether the investments in the projects would not have happened anyway without CDM.

New and Additional Funds under CDM. While CDM is claimed to be able to foster technology and resource transfer from Annex I to developing countries, there is a potential conflict between the Annex I and developing countries' interests. Annex I countries have incentives to channel these transfers as much as possible through CDM, as it will provide CER. Developing countries want to ensure that CDM provides transfers that are additional to normal foreign direct investment (for private sector) and traditional development assistance (for public funds), and that their development priorities don't get short-changed.

Addressing Sustainable Development. Support for sustainable development has been repetitively asserted by the developing countries as the most important element of CDM. Yet, how CDM should provide for sustainable development needs to be clarified.

The Inclusion of Adaptation. The inclusion of an adaptation levy in CDM will increase the price of CER generated through CDM relative to ET and JI (One possible way to collect the adaptation levy is to put a "tax" on the price of CERs per ton). For this reason, developing countries propose to harmonize the three mechanisms - ET, JI, and CDM - so that each of them includes levy on the proceeds to cover adaptation.

\footnotetext{
${ }^{14}$ Humphreys, S. et al. (1998). See footnote 4.
} 
Banking of Emissions Reduction. CERs from CDM after 2000 can be used towards meeting Annex I countries' QELROs in the period between 2008 and 2012. This banking option is designed to encourage early action and does not exist in the other flexibility mechanisms. There is a discussion to harmonize and extend the provision of banking to the other mechanisms as well.

The Inclusion of Forest Projects in CDM. Nowhere under Article 12 on CDM is forestry mentioned as a way to mitigate climate change. Already, however, a number of developing countries are prepared to offer CERs through forestry projects. Currently, the mechanism and methodology to include land use change and forestry under the entire Kyoto Protocol, not only under Article 12 on CDM, are being addressed in the IPCC report on LUCF and in IPCC/SBSTA workshops. The process is expected to conclude at COP-6 in 2000.

Involvement of Private Sector of Developing Countries. Article 12.9 allows for private entities to be directly involved in CDM projects. The division of roles of the private sector and the government is not yet clear. Especially in developing countries where the private sector is yet to be adequately developed, the role of the private entities needs to be supported.

The Role of Developing Country Governments. Given the expectation that CDM will attract resource transfers between the private sectors, the role of the government needs to be defined. Developing country governments expect to play the oversight role, and will need to build criteria for project acceptance.

Bilateral or Multilateral Arrangement. It is not clear whether CDM will be undertaken on a bilateral or multilateral basis. Each of these options has its merits. While a multilateral approach may avoid unequal negotiating position between Annex I and developing countries, a bilateral approach may greatly simplify the mechanism and in turn reduce transaction costs.

The Need for Capacity Building. Developing countries frequently express their concerns over their lack of capacity in assessing, evaluating, implementing, and monitoring CDM projects. They also express deep concerns on the limited awareness of these countries' major stakeholders on the whole issue of climate change and its implications. They assert that capacity building and information dissemination should be an important aspect of the implementation of CDM.

\section{ACCEPTANCE OF CDM: THE INFLUENCING FACTORS}

While CDM is already in the Kyoto Protocol, its political acceptance is far from unanimous. Given its provision for tradable emissions permits, CDM is likely to face similar concerns as those raised by the developing countries of the Joint Implementation (JI) and the Activities Implemented Jointly (AIJ) regimes. ${ }^{15}$ Thus, there are lessons to be learned from the shift of developing countries' position from rejecting JI to accepting CDM.

The Origin of the CDM Proposal. The importance of where the proposal first originated highlights a concern often referred to by developing countries: that of sovereignty and selfesteem. The Brazilian CDF Proposal sought to stipulate compliance of Annex I countries with the provisions in the Kyoto Protocol. This proposal was then elaborated further in G77 and China's internal meetings, and was almost unanimously accepted and supported by the developing country group. The proposal was tabled in the negotiating hall as a developing country proposal. Between this proposal and the final version of Article 12, much was modified

\footnotetext{
${ }^{15}$ Agarwal, A. and S. Narain (1998). (Un)Clean Development Mechanism. New Delhi, India: Center for Science and Environment.
} 
to become what was finally CDM, which strikingly resembles JI. But the final outcome was apparently not as important as the origin of the proposal. CDM is claimed as a proposal from developing countries. This claim gives a strong political incentive for developing countries to accept, support, and operationalize it. Indeed, tabling a proposal from a developing country that was endorsed first by other developing countries enhances its acceptability by developing countries. $^{16}$

CDM is not JI. Although it seems trivial, a key difference between JI and CDM is their names. The JI discourse among developing countries had come to a dead-end. It seemed like no matter what could be improved out of JI, the name was already a political dead-end among developing countries. ${ }^{17} \mathrm{JI}$ was considered as a means for Annex I countries to avoid their obligation to meet their emissions reduction objectives, and make other, weaker countries do so for them. In addition, JI was considered as a way for Annex I countries to get developing countries to participate in global emissions reduction.

The Inclusion of Sustainable Development. The inclusion of a provision to foster sustainable development in Article 12 was a clever political move. This provision is considered by developing countries as what, first and foremost, CDM is about. Indeed, the entire name juggling from JI to CDM is a brilliant political move; no one can disagree with clean development. Especially for environmental agreements such as the Climate Change Convention, when environmental protection is seen partly as anti-development, reassurance that the agreement will not jeopardize the development process in developing countries is imperative.

JI did not explicitly include the notion of sustainable development in it. There has been — and still is - a strong belief that limiting emissions is potentially harmful to the development process. By reassuring that CDM will not jeopardize, and will even enhance, sustained development in developing countries, CDM is seen as more acceptable than JI.

Differing Interests Among Developing Countries. There is a strong opinion among developing countries that there are dominant and rather coercive developing countries among them that are more able to voice their concerns. This concern goes back to COP-1, when a disagreement between some dominant developing countries and the rest led to the dissolution of G77 as developing countries' umbrella group to negotiate. This dissolution contributed to willingness to adopt an offset mechanism in the Kyoto Protocol.

\section{ENSURING WORKABILITY OF CDM}

Addressing Sustainable Development. There is no mention anywhere in Article 12 as to how CDM should foster sustainable development, but most developing countries envision fostering sustainable development as more flow of resources and technology into developing countries from Annex I countries. The dominant view in the discussions that led to tabling of CDM is that

\footnotetext{
${ }^{16}$ Ms. Bernarditas Mueller, head of the Philippines negotiating delegation at COP-4 in Buenos Aires, Argentina, when she was asked whether she and her delegation accepted and supported CDM (November 1998).

${ }^{17}$ Climate Change Convention, Article 4.2, especially paragraph (a), which states that “... Parties may implement such policies and measures jointly with other Parties ..."
} 
sustainable development is first and foremost sustained economic growth. CDM is expected to foster private investment and thus sustain economic growth. The aftermath of the Kyoto Protocol negotiation suggests that the criteria for sustainable development be left to the host countries to determine.

Many, however, feel that a common ground for sustainability criteria is needed. The $\mathrm{CDM}$ projects need to be compatible and supportive of national and local priorities; proponents of the projects should support the existing development policies and priorities set forth by the host country governments. Identification of significant local benefits as well as significant negative impacts of a CDM project (and ways of mitigating them) will ensure that the project is supported. $^{18}$

Certification of Emissions Reduction. Points (b) and (c) of Article 12.5 of the Kyoto Protocol provide the basis for certification of emissions reduction: there has to be "real, measurable, and long-term benefits," and the reduction should be "additional to any that would occur in the absence of certified project activity." From project proponents' point of view, there will be a desire to inflate the emissions reduction from the project.

Determining A Credible Baseline for CDM Projects. The amount of CERs depends on the definition of the baseline. The baseline, or the "business-as-usual" emissions that "would occur in the absence of the project," is a hypothetical future of the emissions without a CDM project. The emissions that would have otherwise been generated are extremely difficult to judge. Without a credible baseline the CER claimed also loses its credibility, which may threaten the CDM concept altogether. Approved projects with inappropriate baselines could result in more, instead of less, emissions worldwide. They would claim more emissions reduction than they actually achieved, and thus allow Annex I countries to emit more than they would otherwise.

There are a number of approaches to determine a baseline, from static to dynamic baselines, and from project-level to sectoral and national level baselines. ${ }^{19}$ So far, the only approach in JI/AIJ project design is an individual project-based baseline. In the initial period of $\mathrm{CDM}$, most developing countries will be discouraged if determination of baselines is too complicated or contentious. Since the local capacity to develop appropriate baseline may be limited, most of the work may depend on foreign expertise. Many developing countries will support a simple method to develop baselines, which their own experts can apply themselves. The project-based method is attractive in this regard.

Some maintain that a national or sectoral baseline could be a much simpler yardstick from which reduction is measured. It also addresses the issue of leakage better. ${ }^{20}$ However, this

\footnotetext{
${ }^{18}$ See Hirst, J., and R. Fecher (1997). Developing AIJ Criteria and Institutions for South Africa. Cape Town, South Africa: Energy and Development Research Center, University of Cape Town. See also Sathaye, et al. (1999), footnote 19.

${ }^{19}$ Michaelowa, A. (1998). "Joint Implementation — The Baseline Issue: Economic and Political Aspects," Global Environmental Change (1998).

${ }^{20}$ The issue of leakage refers to a phenomenon that the emissions reduced by the CDM projects actually result in emissions increase elsewhere. Cutting emissions through a project may result in an increase of emissions outside the boundary of the project. For example, partial forest protection may increase logging in non-protected forests elsewhere since demand remains unchanged. See, for example, Sathaye, J.A., K. Andrasko, Willy Makundi, E.L. La Rovere, N.H. Ravindranath, A. Melli, A. Rangachari, M. Imaz, C. Gay, R. Friedmann, B. Goldberg, C. van Horen, G. Simmonds, and G. Parker (1998). Concerns about Climate Change Mitigation Projects: Summary of Findings From Case Studies in Brazil, India, Mexico, and South Africa. Berkeley: Lawrence Berkeley Laboratory.
} 
may be perceived by developing countries as leading to emissions limitation for them, a proposition that has very little possibility to be adopted.

Determining Additionality of CDM Projects. Determination of additionality needs to consider whether a project would have been initiated anyway without CDM support. The following graph provides a perspective for considering the question of additionality.

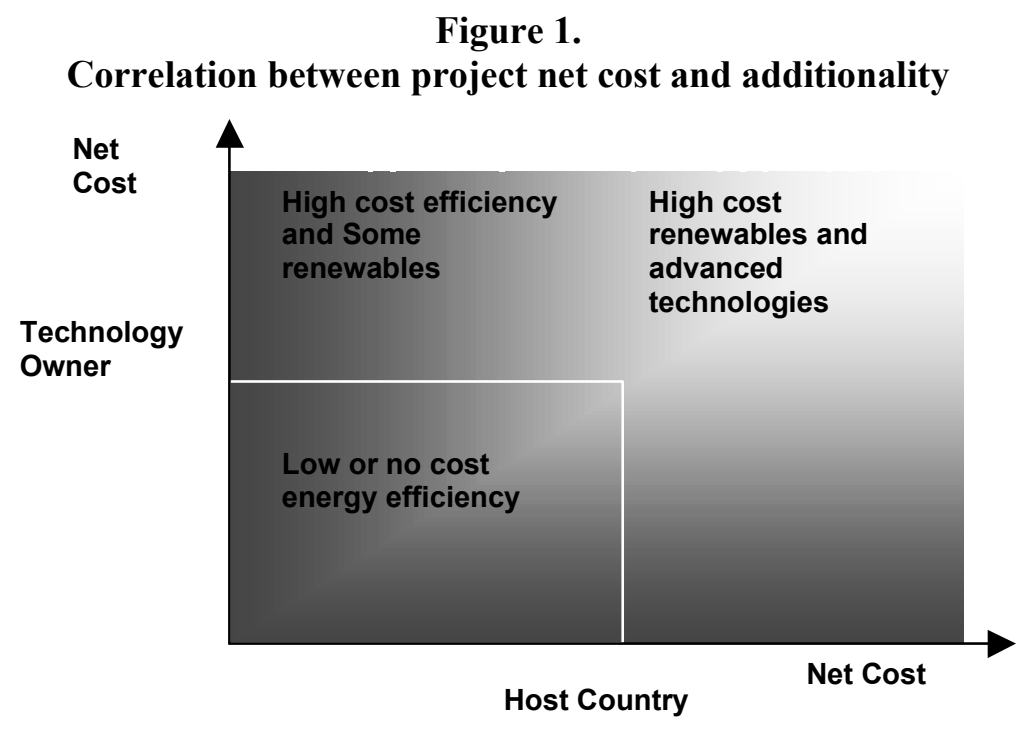

The darkest area in the figure above shows that the lowest cost energy efficiency projects - the "low hanging fruit," or the "no regret" options - are the most attractive for the host countries and the investors alike. The "low-hanging fruit" projects, provide questionable additionality, however, since many of these projects might have been undertaken without CDM investment, since they are already financially viable. The reason as to why these projects are not yet widely undertaken might be due to market imperfection or barriers (such as information gap).

Some high-cost efficiency and some renewable projects may provide benefits to the host countries, but at a cost to the investors, since they may not be financially viable yet. These projects may provide some additionality, but face problems in attracting investment. High-cost renewable and advanced technology projects provide the most additionality, but may cost both the host countries and the investors.

Having too strong additionality criteria may discourage the host country and the investors alike. Having too weak additionality criteria, on the other hand, will give credits for projects that may have taken place without CDM support.

Some developing countries are concerned that if they are required to take on emissions limitation commitment after "low-hanging fruit" have already been picked; that only "highhanging fruit" (costly options) will remain. This could make emissions limitation more expensive for the developing countries in the future. This concern is a reason why some feel it may be appropriate to keep the low-hanging fruit out of CDM, or include such projects in the Interim Phase with a discounted CER. 
Transfer of Technology and Resources. Unless the issues of transfer of technology and resources to developing countries is adequately addressed, the CDM regime will not function. ${ }^{21}$ Both the Climate Convention and the Kyoto Protocol provide many ways to facilitate financial and technology transfer. ${ }^{22}$ The unique feature of CDM is that it returns CER, whereas the others do not. As a logical result, many industrialized country governments may prefer channeling public funds that have traditionally gone through ODA through CDM instead. Understandably, however, most developing countries argue that CDM should not replace bilateral and multilateral aids, and funds should be new and additional. Developing countries fear that CDM might shift the priorities of traditional ODA from more pressing needs such as alleviation of poverty to climate-related projects. Similarly, developing countries also fear that CDM might shift the transfers of private funds from the usual FDI to CDM, and investment priorities could shift toward greenhouse gas mitigation investments.

The most appropriate technology transfer is not necessarily from industrialized to developing countries. Oftentimes, appropriate technologies already exist in developing countries, and there is already a significant capacity starting to develop locally. Diffusion of these technologies may be enhanced by transferring resources to strengthen this local capacity. Another case is that more appropriate technologies are already developed in a number of developing countries, but their application is not wide spread. Potentially, CDM could be utilized to support transfer of technology from one developing country to another, facilitated by Annex I countries.

Inclusion of Levy for Adaptation. Article 12.8 stipulates that a fraction of the proceeds from sale of CERs should be dedicated for adaptation measures in countries that are vulnerable to climate change. Funding of adaptation measures is a feature of CDM that makes it different from the other flexible mechanisms. As a levy for adaptation reduces project revenues, there may be competing interests among developing countries with respect to the size of the levy. While the Brazilian CDF Proposal, the origin of CDM, asked for up to 10 percent of the proceeds of CDF to cover adaptation measures, Article 12 does not explicitly stipulate the fraction to be levied on CDM projects. In addition, some have suggested linking the size of the levy with compliance of Annex I countries with meeting their commitments.

Inclusion of Forest Sink Projects in CDM. The inclusion of removal of greenhouse gases by sinks in CDM is nowhere mentioned under the CDM article and may instigate a long negotiation. Some developing country negotiators argue that since removal by sink is included in the other mechanisms (emissions trading and JI), it should be considered included in the CDM as well. This argument, although logical, has very weak legal basis (although the failure to mention sinks under Article 12 may be an unintentional consequence of a rushed process on the last day of the Kyoto Protocol negotiation). There is a possibility, however, to include sinks in CDM - to harmonize it with the other mechanisms - as a quid pro quo for including adaptation levies in the other mechanisms. At COP-4 in Buenos Aires, the negotiation seemed to proceed towards this outcome. Most forested countries in Latin America and Asia argue for the inclusion of sink in CDM, whereas small island countries generally oppose it.

\footnotetext{
${ }^{21}$ Humphrey, S., et al. (1998). See footnote 4.

${ }^{22}$ Besides CDM, there are other provisions in both the Climate Change Convention and the Kyoto Protocol that provide means to transfer technology. See UNFCCC (1998). Technical Paper on Terms of Transfer of Technology and Know-How - Barriers and Opportunities related to Transfer of Technology. Document No. FCCC/TP/1998/1 (October 6, 1998). Bonn, Germany: UNFCCC.
} 
If the forest projects are included in CDM, the issue of what measures are eligible for credit needs to be resolved. In the Kyoto Protocol, removal by sink of greenhouse gases can only be accounted for through the changes in the forest stock since January $1,1990 .^{23}$ If this definition is used for projects, a measure such as forest conservation cannot be considered as enhancing sink, since there is no actual increase in the forest stock. Only if there is an increase in forest cover by reforestation or afforestation is there enhancement of sink.

Commencement of CDM Operation. CER from CDM after 2000 can be used towards meeting Annex I countries' QELROs in the first budget period, between 2008 and 2012. This "banking" option is designed to encourage early action, and is absent either in emissions trading or JI. The expectation that CDM will produce much CER to be sold and bought in the near future may be too optimistic, however. First of all, there is a substantial possibility that major countries will not have ratified the Protocol to allow it to enter into force by the year 2000. The US insistence for meaningful participation from key developing countries is a deadlocking issue. Developing countries are very unlikely to agree to such a call, at least until demonstrable progress is made by Annex I countries to fulfill their commitments under the Convention and the Protocol. According to the Protocol, demonstrable progress is not due until as late as 2005, although some countries argue that prior to that date, the National Communications from Annex I countries could be a vehicle for evaluating such progress. Some other key countries like the Russian Federation are expected to ratify the Protocol only if the US has done so, since the US is the largest emitter of greenhouse gases. It is unlikely that the Protocol will enter into force by the target for CDM to be operational (the year 2000).

Could CDM be commenced even if the Protocol has not entered into force yet? At COP4, the delegation from Honduras proposed what was later termed an Interim Phase of CDM. The proposal was to start CDM as soon as possible by 2000, provide CERs for the investors, and develop the rules, procedures, criteria, and guidelines along the way. While the introduction of the proposal invited mixed reactions, it emerged in further negotiation as a bridge to go around the constraint of the Protocol not to have entered into force by 2000 or soon after. Some developing countries apparently support this proposal, since it may provide a flow of resources prior to the Protocol entering into force. Nevertheless, the majority of countries, including G77 collectively, feel that clear rules, procedures, criteria, and guidelines necessary before CDM commences operation. Furthermore, they envision that in the Interim Phase, there would not yet be official certification of CERs from projects. Once the Protocol has entered into force, however, retroactive crediting for projects already undertaken would be likely.

Sharing of CER from CDM Projects. While there is a discussion on sharing of the CER produced by CDM projects, there is no explicit provision as to whether developing countries, the hosts of the projects, can make use of the shared CER. The developing countries may want to sell

\footnotetext{
${ }^{23}$ The use of the Kyoto forest definition is strongly welcomed by many industrialized countries that have few forested lands (because of their historical degradation of forest), because they can include their reforestation and afforestation projects since 1990 as enhancement of sink in order to achieve their QELROs. In a number of countries, the potential for sink enhancement is so large that it may actually relax their assigned reduction commitments considerably. On the other hand, heavily deforested countries - Brazil and Indonesia, for example - understandably, prefer to use "business as usual" (meaning continuing deforestation) as a baseline for CDM. In this case, forest conservation projects that halt further deforestation are seen as contributing to sink enhancement.
} 
the shared CER in the future, or bank it for future use if they take on voluntary commitments to limit emissions. $^{24}$

Providing for Capacity Building. Too often, technology transfer is perceived as only in terms of hardware and investments. A number of developing countries point out that a key aspect of technology transfer is local and national capacity building. This means human resource development and institutional building to assess, manage, and apply the most appropriate sustainable technology in developing countries. This sort of technology transfer will happen in the process of partnership between private sectors in industrialized and developing countries, and in some cases may occur even without additional support (e.g. from CDM). How CDM can support transfer of "soft" technology such as increasing know-how, training, and education remains to be defined and divided between the project proponents and the host and the investing country governments, however, partly because the contribution of such projects to real emissions reduction is unclear. Some observers maintain an argument that this is the role of the host government and ODA, but not of CDM.

In all negotiation sessions, the needs for capacity building always comes up as a major concern of developing countries. The capacity building issues can be divided chronologically: capacity building before a CDM project is undertaken, during the project implementation, and self-sustainability of the project, or initiation of similar projects elsewhere, by local institutions.

A key aspect of capacity building is interaction between potential project hosts and investors. Even in the planning stage, foreign CDM project proponents are expected to involve local partners and relevant institutions as much as possible. Particular attention should be paid to the involvement and awareness of the local private sector, since it is expected to be a major player in CDM.

During the course of a CDM project, local capacity to implement, manage, monitor, and evaluate needs to be developed and enhanced by gradually increasing the role of local partners in the project. Developing countries will expect an increase in the role of local partners.

Developing countries will also expect that the ability of local institutions to initiate similar projects elsewhere in the country will be enhanced.

Private Sector Development. Article 12.9 of the Kyoto Protocol states that acquisition of CER may involve private and public entities. The expectation from Annex I countries is that the private sector will dominate the investment, especially since the technology is in the hands of the private sector. In most developing countries, however, the private sector is underdeveloped. Developing countries in which the private sector is strong usually are not the poorest ones, and they have much better institutional infrastructure to deal with FDI. In the poorer ones, the private sector remains weak.

In general, the awareness of the private sector of the issue of climate change itself, let alone of CDM and other mechanisms, remains very weak. Capacity building in developing countries' private sector on the issue of climate change and of CDM is crucial to ensure full, fair, and informed involvement by the private sector in developing countries.

\footnotetext{
${ }^{24}$ Humphreys, S. et al. (1998). See footnote 4.
} 


\section{INSTITUTIONAL ISSUES}

Government Role. Most developing country delegates believe that the involvement of governmental institutions in CDM is necessary. A senior negotiator from Indonesia asserts that the financial crisis that shook Asia was partly due to uncontrolled private sector activities. ${ }^{25}$

There are a number of reasons why governments in developing countries do not completely trust the private sector. One is insecurity of having to compete with more efficient private entities. Another is bitter experience with privatization and uncontrolled private companies engaging in globalized business (such as experienced in Asia recently). Thus, government control and significant involvement of governmental institutions and initiatives may be a prominent characteristic of CDM, at least in its early stage.

Developing country governments will likely want to supervise the entire process and to authorize the involvement of third parties. It is envisioned that developing country governments will play a significant role in prioritization of projects, establishment of project criteria including sustainable development criteria, development of project portfolios, and development of criteria for impact evaluation.

Third Party Involvement. Most likely, the functions of evaluation and verification of the CER will be undertaken by third parties under the auspices of the Executive Board of CDM. Only a few developing countries, however, have either experience in or institutional preparedness for having such third party involvement.

Developing country governments' acceptance of these third parties is determined by a number of factors. Firstly, developing countries would expect a major role in supervising these third parties' operation. Secondly, developing countries expect a mechanism in which international bodies other than the CDM Executive Board will be involved in the process of certifying the appropriate third parties for the services.

Bilateral or Multilateral Arrangements. To ensure that CDM provides the most benefits possible, the flexibility for either bilateral or multilateral agreements in CDM may allow the best deal. As with JI, a bilateral approach allows project investors and host country parties to link project-by-project on a contractual basis. This approach favors minimal use of CDM institutional machinery except a clearinghouse mechanism that puts investors in touch with interested hosts, and an oversight function to provide for an independent certification system. ${ }^{26}$ A potential problem is that there may be unequal negotiating capacity between Annex I and developing countries. Smaller developing countries in particular may have difficulties in rejecting project proposals from powerful private interests.

In a multilateral arrangement, host countries could collectively build a portfolio of projects. Potential investors would look for partnership through a central entity rather than directly to particular countries. A multilateral arrangement would give some sense of security and confidence on the side of the developing country negotiators, because they will be

\footnotetext{
${ }^{25}$ Mr. Aca Sugandhy, personal communication, (November 1998).

${ }^{26}$ Yamin, F. "Chapter 5: Operational and Institutional Challenges,” in Goldemberg, J. (ed.) (1998). Issues and Options: The Clean Development Mechanism. New York: United Nations Development Program.
} 
negotiating collectively, and thus may be favored by some developing countries. ${ }^{27}$ Collective action among developing countries would restrict competition among developing countries, and thus may allow a higher price of CERs. ${ }^{28}$ However, the idea of trying to establish a cartel of CER producers as a way to shield developing countries from the domination of powerful industrialized countries and to reap higher profit for their CERs has been attacked as a hindrance to competitiveness, and may also be unrealistic. ${ }^{29}$ A problems with a multilateral approach is the tendency for a centralized institution to become too regulating in ways not welcomed by private investors.

National Institutional Concerns. In general, climate change is not considered as a priority issue in developing countries. As a result, most institutions in developing countries are largely ignorant of the climate change issue, let alone of CDM. In addition, lack of coordination among various institutions in developing countries is a common problem. Education is imperative to provide for an informed decision-making process in developing countries, one that involves as many stakeholders as possible.

The first requirement is an increase in familiarity of the CDM concept itself (and to some extent, of the whole issue of climate change). In developing countries, communication between the international negotiators and other relevant institutions in the country may not be as fluid as in more developed countries. Exchange of information and of concerns needs to be adequately facilitated. Increasing awareness within developing countries of CDM issues will raise their capacity to set strong but realistic criteria for CDM, as well as to negotiate for a fair deal with potential investors.

Formation of the CDM Executive Board. CDM will be governed by COP/MOP through an Executive Board. The formation of the Executive Board is expected to be a sensitive issue and is highly political, as the prolonged negotiation about the formation of the bureau of COP shows. The first complication might be the issue of equitable representation. While some countries argue that equitable representation means an alternating leadership of the Bureau of the COP between Annex I and Non Annex I countries, developing countries in general argue that geographical representation is more equitable.

The second issue is about scale. Is the Executive Board to direct a large institution such as the UNFCCC Secretariat, or is it to be a small secretariat with most of its work done by third parties and consultants? Can most of the work be undertaken by third parties? How can the interaction and the division of authority be applied between the Executive Board and the third parties?

\footnotetext{
${ }^{27}$ The utilization of G77 as a collective negotiating tool for developing countries, for example, has demonstrated G77's role in supporting equal footing in negotiating, and reducing the overall influence of bilateral geopolitics.

${ }^{28}$ Yamin, F. See footnote 26.

${ }^{29}$ Sari, A.P., in his presentation at the International Workshop on "Dealing with Carbon Credits After Kyoto," Callantsoog, the Netherlands, May 1998, See Sari, A.P. (1998), On Equity and Developing Country Participation. Paper presented at the Workshop on Dealing with the Carbon Credits After Kyoto, Callantsoog, the Netherlands, organized by the Joint Implementation Network and ETS (May 28 - 29, 1998); also, in his talk on CDM from developing countries' perspectives at the 8th Meetings of the Subsidiary Bodies in Bonn, Germany, in June, 1998.
} 


\section{CONCLUSION}

At the international level, the Kyoto Protocol seems to show that CDM is politically and legally accepted by developing countries. This acceptance, however, is not to be taken for granted. To have CDM effectively in operation, continuing support from developing countries is imperative. Such support depends on a number of factors, as follows:

- Genuine respect from Annex I countries for developing country concerns regarding CDM. In particular, Annex I countries need to respect the desire of developing country governments to oversee the CDM process in their countries.

- Rebuilding of trust among developing countries of the intention of Annex I countries regarding CDM. Annex I countries need to demonstrate that domestic actions take priority over flexibility mechanisms in reducing emissions by taking initiatives as soon as possible.

- Effective and substantial transfer of technology and resources to foster and sustain development. Developing countries do not want Annex I governments to transfer normal development assistance into CDM because of the credits to be gained from the latter.

- Equity between Annex I and developing countries and among developing countries themselves so that the benefits of CDM projects are fairly shared between investing and host countries, and that the distribution of CDM projects around the world is geographically equitable. follows:

Regarding the operation of CDM, the dominant developing country perspectives are as

- Establishing criteria to ensure that CDM projects support sustainable development should be left to individual host countries.

- A credible but simple way is needed to determine baselines for and additionality of CDM projects.

- The adaptation levy could put CDM at a disadvantage relative to other flexibility mechanisms. Therefore, developing countries support harmonizing the flexibility mechanisms so all of them fund adaptation measures. Some believe that the size of the levy should be a function of compliance by Annex I countries.

- Perspectives vary regarding the role of forest sink projects in CDM. Some would support such inclusion in exchange for harmonization of the adaptation levy in the other mechanisms.

- Clarification is needed regarding the sale of shared CERs by developing countries.

- There is support among developing countries for commencing CDM as soon as possible. Since official commencement must await the entry into force of the Kyoto Protocol, many developing countries support the establishment of an Interim Phase starting in 2000, with possible retroactive crediting once the Protocol enters into force.

- There is a strong need for capacity building in developing countries to support at all stages of project development and implementation. Particular attention needs to be given to raising awareness and capacity of the private sector. follows:

Developing country perspectives on the institutional arrangements for CDM are as 
- Overall supervision should be undertaken at the COP level, and the formation of the Executive Board should reflect equitable geographical distribution of countries.

- Private sector activity should be under close scrutiny and oversight by the government in host countries.

- Some flexibility concerning bilateral or multilateral arrangements in CDM is desirable. However, it is important to ensure that equal footing between Annex I and developing country parties is not compromised by bilateral arrangements, and that bureaucratic hassle is not prominent in a multilateral arrangement.

- The role of third parties, such as to undertake the evaluation and verification of projects, should be determined as soon as possible. The operation of these entities should be under strict supervision internationally through COP.

- There is a need to strengthen coordination among relevant institutions in the host countries. 